\title{
CORRECTION
}

\section{Correction to: Influences of dielectric and conductive fillers on dielectric and mechanical properties of solid silicone rubber composites}

\author{
B. S. Manohar Shankar ${ }^{1}$ (]) S. M. Kulkarni ${ }^{1}$
}

Published online: 25 June 2019

(c) Iran Polymer and Petrochemical Institute 2019

\section{Correction to: Iranian Polymer Journal \\ https://doi.org/10.1007/s13726-019-00724-4}

The article listed above was initially published with incorrect Tables 1 and 2 values. In this Correction, Tables 1 and 2 new values are given below.

1. In Table 1 (Properties of DDC composites as per Taguchi $\mathrm{L}_{8}$ orthogonal array), the effective resistivity @ $1 \mathrm{kHz}$ for the composite samples are to be read as:

\begin{tabular}{ll}
\hline Sample code & $\begin{array}{l}\text { Effective resistiv- } \\
\text { ity @ } 1 \mathrm{kHz}(\Omega \\
\mathrm{m}) \times 10^{6}\end{array}$ \\
\hline S0 & 6.3 \\
S1 & 5.8 \\
S2 & 6.1 \\
S3 & 5.7 \\
S4 & 5.5 \\
S5 & 6.0 \\
S6 & 5.8 \\
S7 & 5.4 \\
S8 & 5.7 \\
S9 & 5.8 \\
\hline
\end{tabular}

2. In Table 2 (Properties of CDC composites), the effective resistivity@1 kHz for the composite samples are to be read as:

The original article can be found online at https://doi.org/10.1007/ s13726-019-00724-4.

B. S. Manohar Shankar

manoharshankarbhat@gmail.com

S. M. Kulkarni

smk@nitk.edu.in

1 Department of Mechanical Engineering, National Institute of Technology Karnataka, Surathkal, Mangaluru 575025, India

\begin{tabular}{ll}
\hline Sample no. & $\begin{array}{l}\text { Effective resistiv- } \\
\text { ity @ } 1 \mathrm{kHz}(\Omega \\
\mathrm{m}) \times 10^{6}\end{array}$ \\
\hline 1 & 1.5 \\
2 & 1.3 \\
3 & 1.3 \\
4 & 1.7 \\
5 & 1.3 \\
6 & 1.3 \\
7 & 1.6 \\
8 & 1.3 \\
9 & 1.3 \\
\hline
\end{tabular}

The original article have been corrected. 